\title{
Dialectica de los Procesos Subjetivos
}

\section{Subjectivity and Dialectic}

\author{
Guy Santibañez $-H^{1}$
}

\begin{abstract}
Resumen
Este trabajo está dedicado a analizar en una perspectiva dinámica las características más importantes de las funciones subjetivas del Sistema Neuroendocrino. Estas funciones se originan en la interacción entre los individuos de diversas especies y sus medios. Son fenómenos fenotípicos, es decir que están basados en una disposición genética que permite la aparición de la base neural de la subjetividad, pero el contenido de los procesos subjetivos depende del medio o de los medios con los cuales el individuo interactúa. Sin cerebro no hay subjetividad, sin medios en interacción tampoco la hay.

Las funciones subjetivas - subjetividad - son una de las funciones integrativas del cerebro, conjuntamente con la reactividad y la plasticidad.

Durante un largo tiempo la subjetividad fue tratada como un fenómeno peculiar de diferentes denominaciones: mente, conciencia, alma, espíritu. Estas categorías son producto de la reflexión, de fuerte significado ideológico. Todas ellas se refieren a procesos subjetivos.

El cerebro tiene la habilidad de "subjetivar" la información que recibe a través de la codificación de la actividad de los canales sensoriales aferentes. Este fenómeno consiste básicamente en transformar la información en un fenómeno virtual accesible directamente al cerebro que lo produce, y a través de la introspección y el lenguaje, a otras personas.

La subjetividad es un fenómeno psicológico plástico analítico-sintético de carácter histórico. Esta función es capaz de "producir" (imágenes y percepciones) y "reproducir" (percibir sus propias percepciones) los fenómenos subjetivos en una permanente dinámica dialéctica. Oscila entre la «realidad» y la «fantasía», entre la percepción sensorial y la producción más endógena. Es capaz de generar estímulos inhibitorios o excitatorios que pueden operar sobre el Sistema Neuroendocrino.
\end{abstract}

1 Profesor Titular, Departamento de Psicología, Universidad de Chile. gsantiba@uchile.cl 
La subjetividad es el proceso psicológico que permite operar sobre los medios externos e internos de una manera intencional, anticipatoria, predictiva y planificada.

Palabras claves: subjetividad, interacción sujeto-objeto, consciencia

\section{Summary}

This paper analyses the most important subjective functions of the Neuroendocrine System from a dynamic perspective. These functions emerge from the interaction of the individuals of different species with their environments. They are phenotypic phenomena, i.e., they have a genetic basis that allows the expression of the neural framework of subjectivity; thus, the contents of the subjective processes depend on the environment or environments the individual interacts with. There is no subjectivity without a brain, and none without an environment

Subjective functions - subjectivity - constitute one of the integrative functions of the brain, together with reactivity and plasticity.

For a long time subjectivity was treated as a peculiar phenomenon with different denominations: mind, conscience, soul, spirit. These categories are a product of reflection, have a strong ideological significance and all refer to subjective processes.

The brain has the capacity to "subjectivise" the information it receives by coding the activity of the afferent sensory channels. This consists basically in transforming the information into a virtual phenomenon directly accessible to the brain that produces it, and transmitting it to other people through introspection and language. At present, by means of recent tomographic research methods (proton emission, single photon emission, registration of magnetic activity), it is possible to establish correlations between neural activity and subjective processes.

Subjectivity is a historically conditioned plastic analytic-synthetic psychological process. It is able to "produce" (images and perceptions) and "reproduce" (perceive its own perceptions) subjective phenomena in a permanent dialectical flow. It oscillates between "reality" and "phantasy", between sensory perception and more endogenous production. it is able to generate inhibitory or excitatory stimuli that can operate on the Neuroendocrine System.

Subjectivity is a psychological process that permits the operation on external and internal environments in an intentional, anticipatory, predictive and planned fashion.

Key words: subjectivity, subject-object interaction, consciousness 


\section{Introducción}

Este artículo es un intento de presentar las funciones subjetivas del cerebro desde una perspectiva dinámica, como una actividad integrativa del cerebro (Santibañez-H., 1984) de un tipo análogo a la reactividad y la plasticidad (Konorski 1967). Los fenómenos "reactivos" son automáticos, preponderantemente, generados por modificaciones funcionales del tejido neural de carácter bioquímico y biofísico como la excitabilidad, conductividad y la transmisibilidad. Los fenómenos "plásticos", fenómenos de aprendizaje los cuales pueden describirse como la habilidad del Sistema Neuroendocrino de modificar su reactividad en su interacción con el medio y así adquirir nuevos hábitos o reacciones. Los fenómenos "subjetivos", son fenómenos aprendidos, basados en la propiedad del Sistema Neuroendocrino de generar fenómenos virtuales, accesibles directamente al cerebro que los produce y hasta ahora, comunicables indirectamente a otras personas a través de un sistema de comunicación.

Las diferentes funciones integrativas han aparecido en sucesivos estadios evolutivos de las especies dotadas de sistemas neuroendocrinos: un Sistema Nervioso mono o bineuronal genera funciones prácticamente solo de carácter reactivo. La aparición de una o dos interneuronas entre las neuronas aferentes y eferentes permite una actividad plástica de tipo asociativo. Las funciones virtuales o subjetivas aparecen en cerebros de complicadas estructuras neuronales con diversas entradas y salidas neuronales y un sistema interneuronal complejo y flexible.

La historia del estudio de los procesos virtuales muestra que les han sido atribuidas diversas funciones -supuestas o reales-, designadas con diferentes denominaciones. Tengamos presente, entre otras: espíritu, alma, anima, mente, esencia, halito, moral, conciencia, sentimientos, conocimiento. Todos estos nombres se refieren a fenóme- nos operantes en el mundo interno de las personas. Son subjetivos. Este mundo interno, virtual, es rico en contenidos. Hay allí desde imágenes hasta ideas, desde sentimientos a conocimientos, desde impresiones hasta pensamientos, desde percepciones hasta alucinaciones, desde conciencia a automatismo.

Cada periodo evolutivo del Homo sapiens ha favorecido diversos conceptos funcionales. Las sociedades primitivas comunitarias y sus sucedáneos modernos han construido el reino del "espíritu" el cual ha sido considerado requisito esencial de los fenómenos vivientes.

Este espíritu ha sido la única forma de conexión que nuestros antepasados habrían tenido con el mundo natural del cual formaban parte. Era especialmente importante en la obtención de alimentos, como una posibilidad terapéutica, o como medio de control de ciertos fenómenos naturales. Así por ejemplo, el espíritu era la última relación que existía con quienes habían muerto. Los espíritus tenían la facultad de visitar los lugares en los cuales habían vivido. Dejarles presentes era una costumbre muy difundida para recordarles en importantes ceremoniales, etc.

La sociedad primitiva se transformó en una sociedad organizada. La relaciones con los espíritus pasó a manos de un grupo de "expertos", entendidos en estas materias chamanes, machis, brujos, sacerdotes, etc.Los cuales organizaron instituciones permanentes para abordar y desarrollar estas materias.

La discusión acerca de los procesos subjetivos es característica en cada época. En las comunidades primarias se conversaba sobre el espíritu y sus variantes. Durante el feudalismo medieval la polémica ha sido sobre el alma. En la época del capitalismo monopolista transnacional la discusión es sobre la conciencia, la moral y la mente. (Santibañez-H. y Osorio, 1998, 1999). 


\section{Delimitación, Fenomenología y Génesis de la Subjetividad}

El pensamiento formal acostumbra a definir los problemas que trata. Nosotros no estamos interesados en definir nuestro problema, sino más bien en delimitar el ámbito en el cual el fenómeno tiene lugar. El objeto de nuestro trabajo está restringido a la así llamada "experiencia interna" o "mundo interno" de un individuo en interacción con un medio externo, con un medio interno y con su propio mundo subjetivo, el cual le damos la categoría de "medio subjetivo".

Es decir, concebimos el "mundo subjetivo" como un fenómeno en movimiento. La dinámica de la "experiencia interna" viene de la interacción del individuo con el medio interno y el medio externo. Ambas entidades son dinámicas y en consecuencia también las interacciones en las cuales participan. Y, si el "medio subjetivo" es parte de estas interacciones consecutivamente es un proceso dinámico. Esta propiedad hace de la subjetividad un proceso dialéctico.

Una definición implica considerar un fenómeno fuera de sus condiciones espaciotemporales, no necesariamente incluye el movimiento o los cambios implícitos en el fenómeno y por supuesto no incluye ni su génesis, ni su desarrollo. La subjetividad es una neurofunción categorial e integrativa (Santibañez-H., 1976, 1984 p. 43-76), así como lo son la reactividad y el aprendizaje. Es el resultado, entonces, de la actividad de la materia viviente. No surge de la actividad neuronal en abstracto, sino de la actividad neuronal en la interacción de los individuos concretos con elementos (objetos, procesos, fenómenos) pertenecientes a los medios interactuantes. Es la información proveniente de estos medios, adecuada para activar conjuntos de áreas receptoras específicas, la cual es codificada en diversos niveles del Sistema Neuroendocrino.
Entendemos por "subjetivo" todo proceso generado por el cerebro, como una reacción a influjos provenientes de cualquiera de los medios, o simplemente de producción cerebral endógena. En el primer caso el proceso subjetivo refleja o representa fenómenos reales, en el segundo opera con procesos de proveniencia subjetiva.

Los fenómenos subjetivos son virtuales. La génesis de un proceso subjetivo equivale a la virtualización de fenómenos del medio externo e interno y a la revirtualización de un proceso subjetivo ya existente.

\section{Fenomenología de los Procesos Subjetivos}

La génesis de los procesos subjetivos es un factor definitivo para discutir sus características ontológicas.

Tengamos presente que la adaptación la subsistencia del individuo y la especie en determinadas condiciones ecológicas-. es el fenómeno o la condición que ha permitido la evolución de las especies, a pesar de las variaciones, sufridas por los medios externos que han aparecido y cambiado en transcursos variables. Dejando de lado el aspecto genético, los individuos de una especie son capaces de sobrevivir a cambios ambientales si devienen capaces de adoptar nuevas reacciones para afrontar las exigencias del medio que se ha transformado o ha sido cambiado.

Las especies dotadas de sistemas neuroendocrinos, en especial el Homo sapiens, han mostrado una gran capacidad adaptativa, lo cual les ha permitido sobrevivir en condiciones ecológicas extremadamente difíciles, sea debido a cambios climáticos o cambios de hábitat.

La adaptación implica modificaciones tanto comportamentales como subjetivas. Ambos procesos responden integralmente 
a las demandas del medio externo, para lo cual el Sistema Neuroendocrino debe generar aspectos funcionales de ajuste con los medios con los cuales interactúa y necesariamente debe reflejar o mejor generar representaciones tanto del medio externo, como del medio interno y de sus propios procesos subjetivos.

El Sistema Neuroendocrino es el órgano regulador, armonizador de los procesos subjetivos, viscerales y ecológicos. Sin embargo este sistema, como todo el organismo, tiene su base ontológica en fenómenos físicos, químicos, biofísicos, bioquímicos y su desarrollo funcional de ningún modo es autónomo, independiente de las funciones que desempeña en el proceso de adaptación individual. Si el Sistema Nervioso es experimentalmente impedido de ejercer sus funciones entra en un proceso degenerativo. Reflexionar sobre el Sistema Nervioso en abstracto es un camino equivocado para conocer su funcionamiento. Esto es crucial en el proceso de conocimiento de los fenómenos subjetivos. Las funciones integrativas del Sistema Neuroendocrino no se generan en un Sistema Nervioso o en un cerebro abstraído, ni de sus bases fisicoquímicas, ni tampoco de sus funciones de coordinación de la interacción de los individuos con sus medios, incluida la interacción del Sistema Neuroendocrino con el medio subjetivo, con los procesos subjetivos. La subjetividad y el comportamiento son objetos clásicos de preocupación de la Psicología, lo cual hace del sistema coordinador de las funciones ecológicas, viscerales y subjetivo-comportamentales el núcleo básico de los procesos psicológicos (Santibañez H. y Osorio 1998, 1999).

Es interesante hacer un comentario sobre las opiniones de J. Searle $(1990,1992)$ quien se refiere a un fenómeno subjetivo como la "conciencia" de la siguiente manera: "Ante todo la conciencia es un fenómeno biológico. Debemos pensar que la con- ciencia es parte de nuestra ordinaria historia biológica, conjuntamente con la digestión, el crecimiento, la mitosis y la meiosis. No obstante, aunque es un fenómeno biológico, tiene algunas importantes características que otros fenómenos biológicos no tienen". Desde un punto de vista de una lógica elemental la frase citada conlleva una contradicción interna. Si la conciencia tiene otras "características que otros fenómenos biológicos", Searle afirma que es y no es un fenómeno biológico como otros. Lo cual es razonable, pues la conciencia es un fenómeno psicológico, donde se integran los fenómenos biológicos con los ambientales. Más adelante, al ocuparse de la subjetividad, sostiene que es necesario "explicar cómo un set de procesos neurobiológicos puede determinar que un sistema adquiera un estado subjetivo de sensibilidad o conciencia... Lo que propongo aquí es si podemos tener epistemicamente una ciencia objetiva en un dominio ontológicamente subjetivo". Esta afirmación no deja de ser interesante y a nuestro parecer también encierra una contradicción básica. El carácter epistémico de las técnicas científicas son de naturaleza tal que sólo pueden operar sobre entidades reales, sobre configuraciones dinámicas de "materia-energía" y no sobre constructos de ideas carentes de correlatos objetivos.

Tengamos presente que Aristóteles (384302 A.C.) concebía la ontología como una "metafísica general", que Hartmann (18821950) precisó que esta disciplina estudia el "ser en cuanto a tal" y que Jacoby (18811969) la describe como la doctrina del "siendo bajo el punto de vista de su condición, y caracterizó la "nueva ontología ... como la doctrina que no depende de la conciencia cognoscente sino que tiene existencia propia" (Santibañez-H. , 2000). En esta perspectiva es interesante lo mencionado por Searle: El autor afirma enfáticamente (Searle 1992) que la subjetividad está más allá de los recursos descriptivos de la ciencia. Afir- 
ma categóricamente que jamás podrá “existir una teoría de la conciencia, a menos que los irreductibles elementos subjetivos (como por ejemplo los "sentimientos") puedan ser objetivados de manera tal que se alinien con los objetos básicos de la ciencia como átomos, campos de fuerza, etc. Opina que algo que no puede ser observable, no puede ser objeto de tratamiento científico, que la noción de observación presupone la distinción entre la representación creadora de representaciones subjetivas y el caso observado. Según el autor, como la conciencia es accesible a sí misma solamente, nunca se podrá construir una representación objetiva de la conciencia. Searle aconseja "dejar de concebir la subjetividad como parte de nuestra visión, tenerse en el punto que estamos y aceptar los hechos. Estos hechos indican que son procesos biológicos, los cuales producen los fenómenos mentales conscientes y que estos son irreductiblemente subjetivos". Nuestro autor nos propone que estudiemos la "consciencia" al margen de su órgano productor. En esto parece coincidir con Greenberg (1983) quien propone una Psicología sin cerebro.

Los procesos subjetivos se generan cuando, y sólo cuando, el individuo, o si se quiere el Sistema Neuroendocrino individual está en interacción con el medio externo e interno. Esta interacción permite al Sistema Neuroendocrino un desarrollo normal. El aislamiento del individuo del medio externo afecta gravemente la maduración de este sistema. En otros términos, la subjetividad es una función que perfecciona la función neural, es decir, la subjetividad es tanto una función del Sistema Neuroendocrino, como el Sistema Neuroendocrino es una función de los procesos subjetivos y de los procesos efectores entre los cuales incluimos al comportamiento. Por ello debe considerarse al Sistema Neuroendocrino como un órgano psicológico. La subjetivación es una función psicológica. Es la capacidad del Sistema Neuroendocrino de abducir infor- mación, transducirla, codificarla y luego transformarla en procesos virtuales.

Los procesos subjetivos son procesos reales, producto del metabolismo neuronal, pero no de neuronas abstraídas de sus configuraciones anatómicas, de sus interacciones, de sus niveles excitorioinhibitorios, de sus interacciones con conjuntos neuronales que tienen acumulada información abstraída a lo largo de la experiencia. Estos conjuntos neuronales son capaces de configurar el mundo interno, el medio subjetivo. Este medio es virtual, de percepciones sensoriales y subjetivas, de imágenes complejas, de pensamientos, etc. La virtualidad de estos procesos no les impide ser producto de la actividad neuronal. Ellos subsisten - en potencia o acto - tanto cuanto las neuronas generadores funcionan. Muertos estos recursos desaparece el fenómeno virtual. Alterada la estructura neuronal subyacente se altera la subjetividad (como sucede en diversos formas de afasia).

Volviendo a Searle. Al parecer, tiene una concepción muy popular de la actividad científica. Parece creer que hacer ciencia, obtener conocimientos, es exclusivamente el producto del trabajo con la percepción directa del objeto de estudio. No obstante, un fenómeno puede ser conocido en diversas condiciones objetales en relación al investigador: A saber: por percepción directa del objeto, por la percepción de huellas dejadas por el objeto, por la observación de la acción del objeto sobre otros objetos, por la modificación intencional del objeto; la última etapa del conocimiento es adquirir la habilidad para reproducir factualmente el objeto, hacer el objeto. Todos o casi todos los objetos de estudio que envuelven formas de energía han sido conocidos por los efectos que provocan, aunque la percepción directa no haya sido posible nunca. La realidad de un fenómeno no directamente perceptible se encuentra 
muy a menudo en la historia de la ciencia. Pensemos, por ejemplo, en el magnetismo y en la electricidad.

En la actualidad conocemos muchas propiedades de la subjetividad. Esta es una función neural que envuelve la representación directa o indirecta de los trozos del medio envueltos en el proceso de conocimiento. Los procesos subjetivos son manipulables de una manera inhibitoria o exitatoria. Son observables por sus características intencionales, anticipatorias y comunicativas (Ginsburg y Koslowski, 1996).

Como los productos de la actividad neuroendocrina son fenómenos aprendidos, tienen un tiempo de génesis, y cierta latencia para entrar en acción, tienen una cierta duración fásica o tónica, son susceptibles de ser activados o inhibidos, son modulados por los cambios de excitabilidad que afectan al Sistema Neuroendocrino, se alteran si los grupos neuronales específicos envueltos en su producción sufren procesos patológicos, son modulados por los ciclos de actividad-reposo etc. Los contenidos de estos procesos subjetivos son virtuales, esto signifca que aunque como productos de la actividad neuroendocrina son generados en espacio-tiempo real, sus contenidos pueden escapar del tiempo lineal y del espacio real (Knight y Grabowecky, 1995). Esta liberación de la tiranía espacio-temporal permite una reorganización de la experiencia de una manera creativa, personal, novedosa o absurda. Situación que posibilita desde crear una obra de arte hasta formular una hipótesis, que demanda una comprobación. Pero al mismo tiempo puede generar condiciones de alienación.

De esta manera los puntos de vista de Searle parecen no concordar con el estado actual del conocimiento de los fenómenos subjetivos. Estos son fenómenos fenotípicos, de factura individual, resultan de procesos de aprendizaje-intencionales o latentes, epistémicos o empíricos- acumulados en el transcurso de la existencia de cada individuo, los cuales pueden o no ser una representación de la realidad. Son producidos por la actividad del Sistema Neuroendocrino hecho que les confiere una realidad funcional objetiva aunque sus contenidos puedan ser puramente virtuales (Hilgard, 1980).

Searle piensa que los fenómenos subjetivos son ontológicamente diferentes de los fenómenos biológicos. Este dualismo no tiene asidero real puesto que las funciones tienen su origen ontológico en los órganos que las producen. Los fenómenos subjetivos son fenómenos psicológicos en contenido y forma. El dualismo de Searle está un poco "démodé". Los procesos subjetivos son reales pero sus contenidos virtuales, y no son separables de las neuronas.

La subjetividad es una función de Sistema Neuroendocrino. Su forma es biológica, y sus contenidos son ambientales. Es una nueva dimensión de la transformación de materia en energía; un nuevo nivel en la evolución de la materia en el cual un proceso social se vuelve biológico y un proceso biológico se vuelve social. De esta manera se generan los procesos psicológicos.

Uno de los fenómenos subjetivos más sencillos es el de la percepción. Algunos creen que la percepción puede ser tratada como una hipótesis que establece el individuo a partir de la información que actúa sobre su Sistema Neuroendocrino. Es difícil aceptar esta idea, ya que una hipótesis representa un juicio sobre algo. Los elementos analíticos parciales y los elementos noconfigurados de la información sensorial no pueden ser objeto de una "hipótesis" ya que no configuran al objeto correspondiente. Si esta hipótesis es la representación de un objeto ya configurado, entonces no nos ayuda a entender lo que es la percepción. McKay $(1970,1978)$ tiene una explicación 
alternativa. Él prefiere pensar en la percepción como un proceso en el cuál se encuentran representados las ciertas propiedades del objeto que se percibe. En su opinión una persona percibe en la medida que actualiza su potencialidad para poder tomar en cuenta la fuente del estímulo.

Tengamos presente en primer lugar, el proceso subjetivo es un hecho objetivo, en lo esencial es el resultado de la interacción entre el cerebro de un individuo y los medios. En segundo lugar, el cerebro interactúa con tres medios claramente diferenciables: el medio externo o extracutáneo, el medio interno o intracutáneo, y el medio intracerebral o subjetivo (Koref-Santibáñez y SantibáñezH., 1986, pgs. 108-113). En tercer lugar, esta interacción se da en una configuración espacial definida por el campo perceptual en cuanto este es activado. En cuarto lugar, esta interacción tiene una función diacrónica, es decir, comienza en una etapa temprana de la vida de la persona y se desarrolla hasta alcanzar un máximo. Se trata de un proceso de aprendizaje. En quinto lugar, la "percepción pura" del mundo externo no existe, por lo menos no sin una elaboración secundaria, ya que el cerebro procesa toda la información sensorial a través de la cual obtiene los perceptos necesarios, y los cuales se integran con alguna información intracerebral. Lo que existe es una integración subjetiva de varias corrientes informacionales. Para limpiar la información externa se requiere, al parecer, de un largo aprendizaje que puede ser, a veces, imposible. Una percepción visual es una reacción subjetiva aprendida, el producto de la unificación del choque visual con estímulos auditivos, kinestésicos, etc. Cada percepción tiene todas las características de un fenómeno plástico, habituación, (inhibición), generalización, integración representacional, integración en unidades de aprendizaje, sociabilidad, transformación en un estereo- tipo, instrumentación, transferencia, etc. Lo más interesante de la subjetividad es que se trata de una actividad aprendida.

\section{Evolución y Subjetividad}

Las características asociativas y plásticas del fenómeno subjetivo son fácilmente reconocibles en la así llamada experiencia gnóstica. En estudios sobre la configuración perceptual y semántica, algunos autores han descubierto que no todos los elementos contenidos en una categoría tienen un significado idéntico. Rosh (1973) descubrió que existen "categorías naturales" que se componen de un "significado nuclear" compuesto por "casos prototípicos" de la categoría. Una categoría encierra miembros que tienen una semejanza decreciente con el núcleo semántico. Algunos colores designados como rojo son "más rojos" que otros; algunas razas de perros son más representativas para el concepto perro que otras. (op.cit. p 111). Rosh llamó a estos elementos "prototipos naturales" y señaló que en el aprendizaje de nombres de categorías se asocia primero un estímulo predominante (solo después de esto se generaliza sobre otros casos) de modo que los prototipos naturales son el punto clave en la organización de categorías.

El desarrollo ontogénico de las capacidades perceptivas demuestra que las imágenes y la percepción son productos de procesos de aprendizaje que se dan a partir de la experiencia perceptiva, de la integración de esta experiencia con la experiencia acumulada en la memoria.

Como la comunicación permite un acceso indirecto, pero aún así fiable, a la experiencia interna, hay investigadores que han intentado enseñar a hablar a algunos animales. K. y C. Hayes (1971) lograron con gran dificultad enseñarle a un chimpancé algunas palabras ("mamá", "papá", "taza", 
"sobre"). Allen y Beatriz Gardner (1969) enseñaron a la chimpancé Washoe, y más tarde a cuatro más, el lenguaje norteamericano de señales para sordos como medio de comunicación. Washoe logró aprender un vocabulario de 132 signos. Se dijo que era capaz de establecer nuevas combinaciones como "tu entenderme" y "tu sacarme de aquí rápido". Premack (1976) enseñó a la chimpancé Sarah a sacar la ficha deseada entre un grupo de fichas y ordenar hasta cinco fichas en el orden deseado. Estaba principalmente interesado en las capacidades de comprensión del animal. Se le pedía a Sarah distinguir entre una ficha con significado y otra sin significado. Los experimentos de Premack probaron claramente que las fichas eran distinguidas, no por sus características físicas, sino por su contenido semántico. Los experimentos probaron convincentemente que la chimpancé Sarah poseía las habilidades lógicas necesarias para el desarrollo de la comunicación hablada. Rumbaugh, Gill, van Glaserfeld, Warner y Pisani (1975) desarrollaron el idioma artificial "Yerkis", con ayuda de sistemas computacionales, pusieron en acción un sistema similar a un jeroglífico con el cual se pedía comunicar el investigador con el animal o dos animales entre si. De esta manera tenían un medio comunicacional a disposición. Sus experimentos fueron realizados con la joven chimpancé Lana ( 3 años y medio de edad). Lana comunicaba mediante la elección de los botones adecuados. Sue Savage-Rumbaugh, et al, (1978) mostraron que puede establecerse una comunicación simbólica entre dos chimpancés. Todos estos experimentos pusieron en evidencia claramente que los chimpancés perciben diversos procesos subjetivos, piensan, sienten y comunican, así como evocan situaciones no actuales, y virtuales con las cuales pueden manejarse (SavageRumbaugh y cols., 1980).

Estos experimentos indican fuertemente que los procesos subjetivos no se encuen- tran limitados al cerebro humano. Este hecho sugiere que las funciones subjetivas corresponden a un modelo de sistema Neuroendocrino al cual pertenece también el del chimpancé. Esto apunta a que la función integrativa del Sistema Neuroendocrino aparece, en forma elemental en un cierto nivel evolutivo, previo al del Homo sapiens. Surgió mas tarde que la habilidad de aprender.

\section{La subjetividad no es una característica exclusiva del Homo sapiens}

Es una creencia muy popular la de sostener que los procesos subjetivos son un atributo puramente humano. Esta actitud antropocentrica de base puramente ideológica, tiene sus raíces históricas en el cambio de la estructura social que tuvo lugar en el paso de la comunidad primitiva a la sociedad estructurada en clases. Mientras el Homo sapiens formó y se sintió parte de la naturaleza, aceptaba en los hechos, tener una habilidad comunicativa bidireccional entre individuos de la especie y los fenómenos naturales. Con el nacimiento de la sociedad organizada en confrontación con la naturaleza, con la división del trabajo y con la división de los hombres en grupos sociales, aparece también la división de los "espíritus naturales". Estos se jerarquizan de acuerdo con esquemas que permiten un entendimiento ordenado de la naturaleza, y de este modo un mejor acceso a las autoridades espirituales, misión era poner orden en sus dominios específicos. Así fue más sencillo entenderse con Tlaloc, el Dios de la lluvia, que con la masa informe de los espíritus de la lluvia. Se formó, entonces,, una interfaces psicológico-social de expertos en los avatares del Dios de todas las lluvias. Este hecho fue importante, pues los intermediarios terminaron por saber más de algo acerca de las lluvias y adquirieron 
así un merecido respeto en sus comunidades. No quedaba nunca claro si el respeto estaba basado en los conocimientos reales mostrados por los intermediarios o si provenía de su comunicación con la divinidad. Creer en las divinidades por medio de conocimientos reales, ha sido una de las razones por las cuales a los incrédulos de las andanzas de los dioses se les llamó "agnósticos", sin conocimiento. Naturalmente la entidad psicológico-individual responsable de la capacidad de conocer pasó a ser una "entidad espiritual" más o menos inserta en alguna parte del cuerpo o del alma, el espíritu, la conciencia, la cual aún hoy para muchos de los "gnósticos" es de origen divino o al menos extramaterial, lo cual significa no pertenecer al cuerpo.

La subjetividad ha sido la función clásica a la cual se le ha atribuido las propiedades funcionales de almas, espíritus, conciencia o como se quiera llamar. Esto tal vez ha contribuido a negar esta función a los animales. Sin embargo, hay numerosas contribuciones dedicadas al tema, entre otra tengamos presente el trabajo de Walker (1983) acerca del pensamiento animal, y el reciente libro de Franz de Waal (2001) donde compara la opinión de católicos y budistas sobre el particular.

Ahora bien, es un problema importante saber cual es el nivel evolutivo donde aparece el nivel subjetivo de las funciones del Sistema Neuroendocrino. Obviamente los primates poseen la función subjetiva, probablemente se extienda a todos los mamíferos y tal vez a todos los vertebrados. Hay además índices que algunos invertebrados marinos tiene habilidades abstractivas notables. Darwin, junto a muchos otros estudiosos, estaba convencido que "conciencia" puede encontrarse en todo nivel evolutivo (Smith, 1978). Esta hipótesis es difícil de probar.

\section{Propiedades de los procesos subjetivos}

Griffin $(1976,1978,1981)$ propone ciertos criterios, los cuales podrían señalar aspectos de los procesos subjetivos, como el "hacerse consciente" o como el "pensamiento". Señala además que en estos procesos pareciera estar implícita la existencia de una "comunicación intencional" entre dos representantes de la misma especie.

Es necesario tener presente ciertas condiciones para que la comunicación exista. Ella implica un "portador informacional", un "emisor de la información" y un "receptor de la información".

Una señal se convierte en portadora de información, porque el emisor y el receptor han aprendido darle un significado. En otras palabras la comunicación, verbal o no verbal, es un fenómeno concreto cuya característica como portadora de información tiene diversos grados de probabilidad, que dependen de la experiencia que los sujetos comunicantes tienen en común entre si, y con el portador. Mientras más estrecho es el contacto social, más informativo es el sistema comunicativo. La transitividad del portador puede ser uni o bilateral, es decir, cada reacción de un individuo puede ser tratada por el receptor como portador de información, aunque posiblemente no tenga significado para el productor. El vuelo circular de las moscas en torno a un terrón de azúcar podría ser interpretado como su intención de probar el azúcar. En efecto las moscas probarán el azúcar, pero nadie podrá asegurar si querían comunicar sus intenciones (Shaffer, 1976). La liberación de una hormona tiene el mismo significado para el análisis de los procesos subjetivos, pues ésta es claramente un portador de información que, sin embargo, puede provocar una respuesta netamente reactiva y no subjetiva de los sujetos. Intencionalidad quiere decir "hecho con propósito", con finalidad, con una 
meta. Es muy difícil decidir si una acción es un proceso subjetivo o simplemente reactivo, desprovisto de propósito y genéticamente determinado. La categoría finalista llamada por Aristóteles causa final se ha atribuido desde la antigüedad a una propiedad de los fenómenos biológicos. La intencionalidad no es un claro criterio que indique activación subjetiva, ni siquiera en una situación experimental como en el clásico reflejo de salivación. Si observamos a un perro que saliva ante un estímulo, no podríamos distinguir si se trata de una reacción defensiva o alimentaria y por supuesto no podríamos decir nada sobre su involucramiento subjetivo. Si bien los estándares propuestos por Griffin para acceder a los fenómenos subjetivo son probablemente necesarios en no primates, no son suficientes, especialmente cuando el contexto histórico de la experiencia concreta de un solo animal es desconocida. Cuando Griffin habla de "comunicación intencional" está implícito que el animal emite un juicio. El comportamiento puede ser un buen portador de información subjetiva cuando el "juicio - comportamiento" llena algunos requisitos, principalmente que los contenidos del juicio no se restringen a una sola experiencia pasada o presente, es decir que el contexto del "juicio - comportamiento" sea potencial o virtual, aún cuando algunas experiencias sean integradas en estos contenidos. Intentemos dar un ejemplo. Cuando un gato me invita a hacer algo, lo interpreto como una señal de que quiere que abra la puerta. Entonces la voy a abrir. Solo después de haber abierto la puerta puedo saber si este era el objetivo del gato. Es posible que realmente necesitaba usar la puerta, así como puede ser que quería otra cosa. Este proceso puede ser interpretado como una compleja interacción conductual de reacciones instrumentales entre individuos de diferentes especies.

Esch et al. (2001) han estudiado las danzas de las abejas que comunican a sus con- géneres las distancias a las cuales se encuentran fuentes alimenticias, con una metódica muy precisa. Rosin (1978) afirmó que un detenido análisis de los resultados de este tipo de experimentos, no indica necesariamente la existencia de procesos subjetivos en las abejas, aunque utilizan una forma de comunicación análoga a un idioma de símbolos abstractos. Naturalmente estos experimentos no niegan esta posibilidad. Habría comunicación, aunque los mecanismos puestos en marcha por las abejas para transmitir la información fueran puramente reactivos.

La constatación del nivel evolutivo en que apareció la subjetividad es importante para establecer la relación entre estructura neuroendocrina y función subjetiva, como también la relación entre subjetividad e integración neuronal de los procesos plásticos.

Al parecer el comportamiento de las abejas pone en evidencia una clara transferencia de información generada por el Sistema Neuroendocrino. Si esta transferencia no estuviere basada en procesos subjetivos sería muy interesante, pues podría ser una ventana al estudio de una función comunicativa cuya integración neural sería puramente reactiva.

Los procesos subjetivos son reales, pero representan fenómenos virtuales. Son intencionales, justamente porque están comprometidos con los fenómenos que han generado las representaciones virtuales. Como ellos, tienen parámetros espacio-temporales virtuales que pueden adelantarse a los cambios que experimentan los procesos reales, pueden anticiparse a ellos, y predecir los cursos de sus cambios. Como operan sobre el Sistema Neuroendocrino ofrecen la posibilidad de ser comunicados, gracias a diversas posibilidades expresivas. Además pueden ser factualmente reproducidos como procesos creativos tanto artísticos o científicos. 


\section{La Gradiente de Subjetivación: de la Subjetivación al Automatismo}

La interacción entre subjetividad y movimiento es de larga data un proceso que ha llamado la atención de los psicofisiólogos. Cuando hablamos de movimiento incluimos los fenómenos motores que dan origen al lenguaje. Sin embargo, la expresión de un fenómeno subjetivo no es solamente una cuestión de movimientos de la musculatura que controla la emisión de fonemas. Hay otros movimientos concomitantes los cuales de alguna manera intervienen en la comunicación. Hay un antiguo chiste judío, tal vez citado por Freud, el cual ilustra la interacción entre movimientos y procesos subjetivos. En tiempos lejanos sucedió en Basra que Moische, un habitante del barrio judío, fue tomado preso por la guardia de la ciudad, acusado de robo y llevado ante la justicia. Moische compareció ante el Cadi para escuchar su sentencia. El juez, siguiendo las normas tradicionales, le impuso la pena correspondiente: amputación de ambas manos. Moische suspiró, y dando una mirada triste dijo resignadamente "Oh Dios mío, ¿Cómo voy a hablar ahora?". Cualquier estímulo capaz de activar reacciones perceptuales es procesado por el Sistema Neuroendocrino de una manera integrada, con estímulos sensoriales de diferente modalidades, generados por el ambiente, además de las propiocepciones derivadas del reflejo de enfoque. Por otra parte, un niño en sus primeros años de vida, frente a un estímulo suficientemente interesante, tiende sus manos hacia el objeto. La persona que ha mostrado el objeto oye decir: "déjame verlo" si se responde al niño: "Pero si lo estás viendo". Este hace un gesto de extrañeza y puede responder: "quiero tocarlo". Efectivamente explora el objeto utilizando otras modalidades sensoriales, además de la visual. Un percepto interesante estimula la necesidad de explorar el objeto correspondiente.
Setchenov en 1863 (1965) se preocupó de las relaciones entre movimientos y procesos subjetivos. Citaremos en extenso algunos de los juicios del célebre antecesor de Pavlov. "La asociación es una serie ininterrumpida de encadenamientos entre el fin de un reflejo y el comienzo de otro. El fin de un reflejo es siempre un movimiento, y este último se acompaña siempre de una percepción muscular" (op.cit. p.170). El proceso de memorización o fijación mnémica se consolida por la repetición de la asociación, de manera tal que la evocación de una parte de información perteneciente al conjunto subjetivo perceptual activa o reproduce la totalidad del fenómeno. (op. cit. p. 171).

He aquí un ejemplo interesante tomado por Setchenov del campo de las percepciones cutáneas: "conozco una persona que es capaz de provocarse la carne de gallina, aún en una habitación caldeada; le basta imaginarse que tiene frío", (op. cit. p.174). En este caso la percepción activada por la imaginación produce un ejemplo idéntico al de una excitación perceptual real.

"Entre la impresión real y sus consecuencias, y el recuerdo de esta impresión, no hay en realidad ninguna diferencia en cuanto a la naturaleza del proceso" (op.cit. p. 174). Es el mismo reflejo psíquico, sólo que los estímulos difieren: la percepción sensorial se produce por acción del estímulo del medio externo, mientras que la percepción subjetiva, previamente adquirida, produce una activación del mismo patrón neuronal que la percepción sensorial percibida directamente.

Frente a la cuestión de cómo surge el pensamiento, Setchenov (op. cit. p. 179-191) constató dos hechos básicos de la actividad muscular. Esta puede ser activada o ser inhibida. Tanto los procesos musculares excitatorios como los inhibitorios operan sobre grupos musculares que trabajan asociados en conjuntos funcionales. La habili- 
dad de excitar o inhibir selectivamente determinados grupos obedece a procesos de aprendizaje. "Por lo tanto, mientras que por repetición frecuente de reflejos asociados, el hombre aprende a agrupar sus movimientos, adquiere igualmente (por la misma vía refleja) la capacidad de inhibirlos. De ahí proviene esa sucesión inmensa de fenómenos en que la actividad permanece exteriormente inexpresada bajo forma de pensamiento, de intención, de deseo, etc." (op.cit p. 186).

Setchenov (op.cit p. 156) propone una hipótesis con respecto a las bases neurales del pensamiento, a la capacidad de pensar. La inhibición de la fase efectora (el último eslabón) de un reflejo es "la facultad de pensar, de reflexionar de razonar".. "El pensamiento es los dos primeros tercios de un reflejo psíquico". Sostiene que "el pensamiento es extremadamente subjetivo".. la historia de su desenvolvimiento indica que reposa sobre toda la experiencia perceptual, procedente de todas las áreas sensoriales, las cuales aún teniendo un origen objetivo, pueden hacerse subjetivas e incorporarse a las corrientes de pensamientos (op.cit p. 188, 189).

El problema de la separación intrasubjetiva del pensamiento y la actividad motora correspondiente, fue discutido por Setchenov: "Aunque el pensamiento se refiere a cosas concretas, a representaciones e imágenes, no por eso deja de ser subjetivo. A todos nos sucede que, bajo la influencia de una excitación sensorial, el proceso subjetivo siga su curso. El pensamiento, luego de una segunda interrupción, puede aún continuar y la acción permanecer inhibida, pero bajo la influencia del pensamiento mismo, puede que el proceso psíquico termine su ciclo, generándose una respuesta concreta. El pensamiento y la acción se separan. Habitualmente la asociación entre dos actos es considerada una relación causal (post hoc, ergo propter hoc). El pensamiento es naturalmente tomado por la causa inicial del acto, sin embargo, esto es la más grande mentira. La causa inicial de todo acto psíquico se encuentra siempre en una excitación sensorial exógena. Entre los reflejos psíquicos, hay muchos cuyo último eslabón es inhibido" (op.cit p. 190).

Tanto sobre Setchenov 1863. Veamos la opinión de P. Janet en 1921.

Janet en su famoso trabajo (1921) al tratar la relación entre movimiento y procesos subjetivos comenta: "Pensar, decía en efecto Bain, es abstenerse de hablar y de actuar. Eso es justo para nosotros que podemos inhibir (los movimientos), pero para los individuos que describimos, pensar es hablar y actuar" (op.cit p. 199). Janet en el trabajo citado estudia los fenómenos sugestivos en diferentes pacientes bajo hipnosis. “Nunca se podrá estudiar más fácilmente esta acción del pensamiento sobre el movimiento, tanto bajo las influencias sugestivas como en condiciones espontáneas, que en esos individuos cuya conciencia está restringida y en consecuencia tienen anestesias numerosas y consecutivas amnesias" (op.cit p.199). "La conciencia de estos enfermos está de tal manera restringida que puede contener solamente un solo fenómeno a la vez; este hecho se presenta bajo la forma de percepción o imagen y, estudiando las acciones de los individuos catalépticos, podemos observar el automatismo de las imágenes subjetivas. El autor llama a este fenómeno "automatismo perceptual".

Janet (op.cit p.482), después de haber observado la configuración de fenómenos sugestivos de inducción positiva (hacer algo, decir algo) o de inducción negativa (anestesias), en diversos tipos de personas concluye diciendo: "En una palabra, independientemente de la perspectiva en que uno se coloque, no hay dos facultades, una, el pensamiento, la otra, la actividad; no hay más que un solo y el mismo fenómeno que se manifiesta de dos maneras diferentes. Se 
trata de la misma cosa que es conocida y estudiada de dos maneras diferentes".

Es interesante destacar que Janet, 60 años después de Setchenov, llega a una conclusión análoga en lo que respecta a la relación moviemiento-pensamiento, a pesar de haber seguido un camino completamente diferente. Sin embargo para, Setchenov el cerebro es responsable en su totalidad tanto de los fenómenos subjetivos como motores. Janet piensa que son fenómenos de dos dominios científicos diferentes: la Fisiología y la Psicología. Formula una hipótesis general: la conciencia se desagrega, de manera que pierde la unidad funcional producto de su "actividad sintetizante. De esta manera se generan los "fenómenos subconcientes", elementos separados de la conciencia general, los cuales son automatismos (Jacoby 1991; et al., 1997).

La unidad "subjetiva-comportamental", o sí se prefiere, la unidad "virtual-instrumental", es la base de los procesos adaptativos ontogenéticos. La repetición de las condiciones en las cuales transcurren los procesos adaptativos o experimentales conduce a la perfección de los movimientos que el medio demanda y, al mismo tiempo acorta el tiempo en el cual el conjunto perceptual es capaz de desencadenar el movimiento. Esto siempre que contribuyan a la adaptación o satisfagan una demanda motivacional. En el caso opuesto, sucede lo contrario: el estímulo se hace inefectivo y el movimiento no aparece. En el primer caso el conjunto perceptual queda estrechamente ligado al movimiento; en el segundo caso se disocian, se desligan.

A medida que el primer caso se repite hay una modificación de la relación estímulo perceptual- movimiento. Hay un aprendizaje consistente en que cada vez el estímulo se hace efectivo cuando solo una parte del mismo ha entrado en acción. El movimiento es activado con el mero comienzo, con el esbozo inicial del conjunto perceptual, o con una situación que tenga alguna relación asociativa con el, como por ejemplo, la decisión de necesitar el movimiento. Hemos denominado este fenómeno: la situación "pars pro toto", que es característica de un proceso de automatización. El componente subjetivo o virtual lentamente puede hacerse innecesario para ajustar el movimiento a la situación. Este ajuste se hace automático y corre sin participación de la subjetividad. Las reacciones automáticas se caracterizan, porque la componente motora sigue un curso sin intervención del correspondiente proceso subjetivo. Aún más, la subjetividad puede estar activada por cuestiones totalmente diferentes a las que interesan a la reacción motora. Esta puede reaparecer si la fluidez del automatismo es impedida por una situación imprevista o perturbadora.

Por su parte, el movimiento, una vez disociado del contexto perceptivo original, puede reaparecer circunstancialmente si se configuran elementos medio ambientales que de alguna manera sean análogos al conjunto perceptual original. Esto puede suceder sí la unidad subjetivo-comportamental ha estado fuera de acción por periodos muy largos. Una vez ejecutado el movimiento, el proceso subjetivo puede ser reactivado como un recuerdo de la situación anterior. La reacción motora puede ser comportamental, verbal o simplemente activada por algún estímulo ambiental.

La mayor parte del control del medio interno se regula de una manera automática. Algo similar sucede con actividades efectoras aprendidas (verbalizaciones, movimientos), las cuales envuelven en sus comienzos reacciones subjetivas. En la medida que estos aprendizajes se perfeccionan alcanzando un nivel de consolidación muy sólido, el proceso efector se disocia de su componente subjetiva. Los estímulos que los activan no necesariamente alcanzan los niveles de subjetivación. 
Las percepciones, o mejor la percepción de un objeto discreto, no son sólo el producto de la activación de neuronas que reaccionan a modalidades sensoriales simples como temperatura, luz o sonidos sino son el producto de la actividad de una serie de neuronas ubicadas a diferentes niveles del Sistema Nervioso, las cuales divergen o convergen sobre diversas neuronas. Estas disposiciones estructuradas de las neuronas permiten al sistema neuronal, envuelto en el proceso, analizar y sintetizar "cuantos informacionales" incorporados al percepto (Santibañez-H. 2001). Como ha sido demostrado hace mucho tiempo, en el cerebro hay estructuras celulares que poseen la incondicionada capacidad de reaccionar ante líneas, bordes, esquinas, palos, lenguas (Hubel y Wisel 1961, 1965); estas neuronas convergen sobre conjuntos de unidades neurales ubicadas en un piso superior del Sistema Neuroendocrino, donde se van integrando los datos codificados con datos apartados por otras neuronas (Konorski 1967, Barlow 1995). De esta manera la codificación de la información sensorial analizada e integrada en algún sistema perceptual, se convierte en un fenómeno virtual. Este fenómeno virtual reproduce con cierta fidelidad las características más sobresalientes del fenómeno percibido, que han sido entregadas en la información correspondiente. La percepción se perfecciona en la medida que ella es repetida. La percepción primera de un objeto es una abstracción del objeto, pues la información así obtenida ha transmitido los rasgos más sobresalientes del fenómeno. En la medida que la experiencia perceptiva se repite, la representación virtual del objeto se va enriqueciendo en connotaciones y va lentamente perdiendo su carácter abstracto. Alcanza así un grado de concreción que puede llegar a reproducir con éxito al objeto percibido..

Hay un segundo elemento en la formación de la "percepción endógena o subjeti- va", la cual resulta de la incorporación de la percepción primaria o sensorial al flujo neural. Si en el cerebro existe una percepción subjetiva previa similar a la de reciente creación, el Sistema Neuroendocrino las integra. Si no existe nada similar, la nueva percepción sensorial es integrada con la percepción subjetiva existente que guarda la mayor similitud en la nueva. García Marquez en "Cien Años de Soledad" cuenta que los habitantes de la selva tropical colombiana la primera vez que vieron una locomotora la describieron como una «estufa con ruedas». Esta no es una historia inventada por el autor, sino una buena observación antropológica (Levi-Strauss, 1973).

La percepción es, al igual que toda función integrativa del cerebro, un momento de un desarrollo histórico, un proceso.

Lo que hemos descrito es el primer nivel de subjetivación. Hay otros niveles. La existencia de una percepción sensorial subjetivada, portadora de información, puede ser integrada a un contexto perceptual existente, pasando a constituir una nueva percepción subjetiva, la cual es diferente de cada una de las que se han integrado, en un nuevo contexto. Este es un fenómeno muy interesante, porque los procesos subjetivos producidos se reproducen. Sea esto por integración o por desintegración, como proponía Janet. Cada estado reproductivo determina un cierto nivel de subjetivación.

La llamada "experiencia interna", "mundo subjetivo" o "mente", es un inmenso cauce de procesos subjetivos integrados en gradientes subjetivas que tienden a su permanente reproducción (Fischer, 1975).

Tanto la subjetivación primaria como la subjetivación reproductiva son procesos de aprendizaje, que implican tanto la generación de nuevos hábitos como la eliminación de antiguos. Cuanto mayor es la consolidación de un proceso subjetivo, más difícil es su modificación; de esta manera su ac- 
tualización es más económica desde un punto de vista de la cantidad de información necesaria (Cutting 1987).

La transformación asociativa de una percepción puede ser considerada como un eslabón más elevado del proceso de subjetivación. Si una percepción tiene un significado adaptativo, es decir, si a través de ella, de una manera directa o indirecta, se puede satisfacer una motivación, tiene esta representación subjetiva que estar dotado de una cantidad tal de connotaciones que sea fácilmente diferenciable de objetos de características similares. En este nivel de subjetivación hay formas de asociaciones que operan a un nivel puramente subjetivo. Recordemos las "asociaciones percepto-verbales-perceptuales", por ejemplo. La existencia de estas asociaciones ha sido puesta en evidencia experimentalmente. Todo el mundo sabe que la descripción de un limón evoca la imagen de la fruta y activa la salivación correspondiente. Este fenómeno es muy interesante, porque la "percepción limón" no sólo reproduce la imagen sensorial de la fruta sino el efecto que ella produce en el organismo. La instrumentalización de un proceso subjetivo corresponde a un grado muy elevado del nivel de subjetivación. Ella puede ser dirigida al medio interno, o puede jugar el rol de un estímulo subjetivo capaz de poner en marcha procesos de verbalización comunicacionales, o facilitar la formación de planes para alcanzar metas o cumplir propósitos. Así la producción subjetiva comienza a operar en el ámbito de las probabilidades, de las virtualidades $\mathrm{y}$ potencialidades.

\section{De la Imagen e Ilusión al Pensamiento Gnóstico y a la Desintegración}

La génesis y desarrollo de los procesos subjetivos no pueden ser conocidos sin considerar que cada ser vivo y su medio interno y externo se encuentran funcionalmente integrados en un ecosistema (Santibáñez-H 1986, p. 111). El ecosistema de una especie social se compone principalmente de elementos culturales y sociales del medio. Marx y Engels destacaron que los seres humanos no son más que meras abstracciones fuera de su mundo (Marx y Engels, 1969, p. 25). Este ecosistema tiene una expresión concreta en la interacción interconductual (Smith 1984) e intersubjetiva, una especie de pegamento que mantiene unidos a los elementos de la red social. La comunicación, verbal y no verbal, conecta intersubjetivamente a los individuos, siempre que esté referida a un medio que se comparte total o parcialmente.

¿Que es lo que está representado en los procesos subjetivos, como por ejemplo en la percepción? Ellos representan la estructura del medio en relación a los objetos. Las percepciones son el resultado del aprendizaje que realiza el cerebro al integrar la información proveniente de la fuente. Este aprendizaje no solo recibe información exógena sobre la fuente-objeto, sino también informaciones que provienen al mismo tiempo de otras fuentes. Lo más interesante es que puede integrar a ella información endógena que ha sido producida por el cerebro mismo. Por esto la percepción en particular, y la subjetividad en general, pueden seguir dos direcciones evolutivas: una que refleja principalmente al objeto, y otra, que esencialmente integra información endógena; es decir en dirección reflectiva o alienante. Así, las imágenes y la percepción pueden ser mas o menos ilusorias. Oscilan entre realidad e ilusión, entre reflexión y extrañamiento. Por esta razón, es un serio error llamar hechos gnósticos a los hechos subjetivos (Santibañez-H., 2001). Imaginarse una sirena no es lo mismo que tener el conocimiento sobre el mundo externo. Esta sirena es de producción endógena. El camino del extrañamiento o alienación puede llevar de la ilusión y externalización, a través de la 
alucinación y locura, a perturbaciones patológicas del pensamiento (Frith,1979; Phillipson y Harris, 1985). El camino reflectivo lleva de la imagen y la percepción, a través de la delimitación del mundo subjetivo, al pensamiento en el sentido gnóstico. Como ambas formas de elaboración integran la realidad en diferentes proporciones, solo hay que pensar que el Homo sapiens ha superado las limitaciones del pensamiento mágico o salvaje, creando un complejo sistema procesal para separar la ilusión de los hechos: la metodología científica, específicamente el método inductivo y deductivo. Sin embargo, el conocimiento puede solo ser adquirido en la medida que exista contacto directo con el objeto, y no con ideas acerca del objeto, es decir cuando en la práctica se puede modificar el medio de manera predecible (Engels 1969, p. 276-296; Marx y Engels 1969, p. 5-7). La subjetividad como tal no es una función gnóstica. Puede ejercer una tal función, cuando elabora la información en forma reflexiva, lo cual a su vez, es solo posible cuando existe una interacción permanente entre el sujeto y el objeto de conocimiento. Esta interacción deviene gnóstica sólo y cuando sólo ella permita a quien conoce, predecir el comportamiento del fenómeno estudiado, interferirlo intencionalmente y en último término crearlo, recrearlo o producirlo.

\section{Subjetividad y Abstracción}

La curiosidad, búsqueda e investigación deben ser consideradas como necesidades básicas para los seres vivos (Konorski, 1967, p. 16-18, 36-39). Las radicales diferencias entre la vida intelectual y emocional tienen una raíz común. Las diferencias entre la pulsión del hambre y una pulsión de información, no son mayores que, entre las pulsiones de hambre y de miedo. Los impulsos informacionales generados a partir de las necesidades informacionales, curiosidad, necesidad de saber, etc., tienen el mismo significado psicofisiológico de cualquier necesidad homeoestásica. Son generadores de las reacciones preparatorias reacciones efectoras (conductuales y viscerales)- originadoras de las reacciones necesarias que llevan al objetivo, lugar donde tiene lugar la reacción consumatoria encuentro y recepción de la información buscada-. Esta reacción consumatoria informacional, contrariamente a lo que sucede con las reacciones consumatorias homeostasicas, no inhibe el impulso, por el contrario, generalmente lo acrecienta y lo prolonga. Esta situación se observa con claridad meridiana en la actividad creadora (artística o científica). Así sucede también, porque el refuerzo-homeostasis es generalmente concreto, mientras el refuerzoinformacional es abstraído del objeto en referencia, es perceptivo. Como hemos señalado, la percepción lleva al conocimiento, y el conocimiento sigue llevando a la percepción. El refuerzo informacional entra al flujo neural configurando elementos mnémicos, al medio subjetivo y no al medio interno, como sucede con los refuerzos homeostásicos. El presentar un cierto quantum de abstracción con respecto al objeto es lo que impide la saciedad informacional.

Por otra parte, la abstracción es una característica de todas las funciones integrativas del Sistema Neuroendocrino. I.P.Pavlov (1953) señaló que el cerebro es capaz de sintetizar y analizar información proveniente de los medios interno y externo. Este análisis comienza en los receptores, limitados al ámbito de su capacidad de reaccionar a las variaciones energéticas del mundo externo. Discriminación y generalización representan el nivel plástico de las capacidades analíticas y sintéticas del cerebro. La abstracción representa el nivel subjetivo de la función cerebral: la unidad dialéctica de análisis y síntesis. Esta integra- 
ción entre análisis y síntesis que se da dentro del proceso de abstracción no es necesariamente simétrica, sin embargo la "virtualidad" del proceso ocurre solamente al interior de nuestro cerebro. Esta "separación virtual" es necesaria para el análisis de objetos que pertenecen al mundo externo (Hintzman, 1986). Por otro lado, el proceso de abstracción lleva operar con ideas, ya que los elementos sintéticos subjetivos (Marx y Engels, 1973, p. 532, 447), que tienen una existencia autónoma, pueden operar con independencia del mundo externo. Este "reino de la abstracción" se basta a si mismo, mientras no sea confrontado con el objeto (Marx y Engels, 1973, p. 218).

Puesto que los productos de la abstracción pueden ser directamente comunicados, existe la posibilidad de realizar un intercambio comunicativo con una débil o en absoluto desarrollada capacidad de reflejar el objeto. Así los productos subjetivos pueden no reflejar las propiedades de un objeto al cuál se refieren. Mas aun, pueden no tener significado cuando adoptan una forma abstracta. No son más que una forma abstracta sin el contexto de la acción real y su contenido no es más que la abstracción de contenidos, en otras palabras, son contenidos creados (Marx y Engels, 1973, p. 585). Este tipo de producción subjetiva no es más que una forma vacía sin un contenido real, justamente el "reino de la abstracción" (Engels y Marx, 1974, p. 60). En otras palabras, los fenómenos subjetivos pueden no referirse necesariamente a objetos del medio; pueden ser productos de abstracciones sin significado gnóstico. Ilusión, extrañamiento, alucinación y locura, pertenecen todas a este tipo de abstracción. Esto es lo que Marx y Engels llaman, falsas abstracciones: "Dicho de otro modo hay abstracciones capaces de reflejar los objetos en sus características más sobresalientes "abstracciones verdaderas", mientras que otras no poseen dicha propiedad.
Existe un segundo tipo de abstracción. Hasta ahora hemos hablado de la abstracción de las ideas, pero también existe una abstracción figurativa. La fotografía de una gato representa a una gato específico. Un artista puede representar a un gato a partir de sus rasgos distintivos, también puede representar una serie de gatos construyendo un dibujo que reúna los rasgos comunes de todos los tipos conocidos de gatos. Esto querría decir que el dibujo tiene una amplia variedad de connotaciones sensoriales para representar una imagen realista de los gatos. Estas connotaciones podrían encerrar solo una o dos características generales. Animales abstraídos se encuentran en los dibujos orientales, por ejemplo en China, pero también en las pinturas rupestres Cromagnon, de Altamira y en Kasachastan (Medoev, 1979). Mientras la figura permanezca dentro de los limites del proceso reflexivo, el objeto al que se refiere puede ser fácilmente identificado.

Los objetos del medio interno o intracutáneo, como los cambios orgánicos, los cambios vasculares, la concentración de azúcar en la sangre, etc., son estímulos que pueden alcanzar el aspecto subjetivo de la función cerebral por medio de la producción de algo que comúnmente se llama "humor". Los aspectos subjetivos de la experiencia emocional son principalmente efecto de una retroalimentación propio-interoceptiva de la reacción que fue activada por medio de estímulos emotógenos (Santibáñez-H., 1976; Santibáñez-H., Bloch, 1986; Bloch, Orthous y Santibáñez-H., 1987).Estos fenómenos han sido poco investigados desde el punto de vista de la abstracción probablemente, porque tal vez la abstracción ha sido considerada un fenómeno gnóstico, lo que parecería inadecuado para el análisis de las emociones. 


\section{La Subjetivación como Medio Virtual: sus Funciones}

¿Qué es la subjetividad?. Es el conjunto de los fenómenos virtuales productos del proceso de transformación que sufren las informaciones tanto pertenecientes al medio interno, como al medio externo, los cuales después de activar las superficies receptoras del organismo sufren una primera transformación en energía bioelectrica codificada por las neuronas -células nerviosas-, las cuales constituyen sistemas funcionales de significado específico. Estos grupos funcionales tienen como misión general coordinar los medios con los cuales los individuos interactúan, operando sobre ellos de manera tal que sus variaciones, las cuales son inevitables, se mantengan dentro de ciertos límites compatibles con diversos equilibrios necesarios para subsistir en condiciones que podemos intentar calificar de "normalidad". Esta coordinación puede llevarse a cabo sólo si los sistemas funcionales configuran un panorama de los medios reales reflejados en el medio virtual.

El medio subjetivo envuelve virtualmente a nuestros organismos, y como cualquier medio, está siempre presente. Es un constante flujo de ideas, imágenes, conceptos, algunos de los cuales vienen del pasado, otros que simplemente están, o acontecerán en ciertas condiciones que deben cumplirse en el futuro; hay proyectos, deseos, circulan personas. Este flujo de acontecimientos parece tener una dinámica propia, siguen líneas asociativas imprevistas. Sin embargo, en condiciones normales no producen ninguna impresión caótica. Tienen un cierto orden. A veces se enganchan a fenómenos que los vinculan a los medios objetivos.

Lo más importante de este medio subjetivo, tal vez una de sus características más notables, la cual le confiere la condición de medio, es su capacidad de activar el Sistema Neuroendocrino, generando reacciones discretas las cuales pueden operar sobre el mismo medio subjetivo, sobre el medio externo o sobre el medio interno. Estos estímulos pueden ser operativos sobre la marcha, o hacerse efectivos con una latencia variable. Hay planes que tardan mucho tiempo en convertirse en acciones. Otros quedan en proyecto, incorporados a la dinámica subjetiva. Los individuos pueden aprender a acomodarse, a adaptarse a sus medios subjetivos, como se acomodan a sus medios externos e internos. Pero al contrario de estos dos medios, sus contenidos son virtuales, ideas o imágenes intencionales, anticipatorias y probabilisticas. Algunos elementos de este medio se instrumentalizan convirtiéndose en realizaciones que operan sobre el medio externo o interno.

El medio subjetivo oscila permanentemente entre la reflexión de los hechos y la alienación de las abstracciones (Parks, 1986). Comúnmente este medio subjetivo tiene dos nombres: "mente y conciencia". Mente (del latín mens, mentis) en nuestro idioma, es una forma de designar las habilidades intelectuales del alma que implica propósito, voluntad, designio o pensamiento; mientras que conciencia (del latín conscientia), sería la propiedad del espíritu humano de reconocerse en sus atributos esenciales y en todas las modificaciones que en sí mismo experimenta tales como el conocimiento interno del bien y el mal, o el conocimiento exacto y reflexión de las cosas (Diccionario de la Lengua Española 1856).

Tanto el concepto de "mente" como el de "conciencia" se refieren a procesos vinculados con el alma o con el espíritu en el ejercicio de funciones intelectuales que implican el conocimiento de preceptos morales o la reflexión, y el conocimiento de las cosas. Son entonces procesos plenamente subjetivos, los cuales serían parcialmente 
responsables de motivaciones, pensamientos, del conocimiento de ciertas normas morales y de los reflejos subjetivos de la realidad. En nuestra lengua, conciencia comprende tanto el conocimiento de las reglas morales como el conocimiento del medio externo. En alemán o en ingles hay una palabra para el aspecto moral y otra para el conocimiento del medio externo. Tradicionalmente tanto mente como conciencia tienen una fuerte componente ideológica. En castellano la palabra "agnósti$\mathrm{Co}^{\prime \prime}$, se usa también como sustantivo, sirve para designar a las personas que no son creyentes, lo cual equivale a negar que el entendimiento humano tenga acceso a toda noción de lo absoluto o divino (agnosticis$\mathrm{mo})$, y por lo tanto indica la permanencia en un estado de desconocimiento o ignorancia.

Estamos proponiendo designar como "subjetivos" a los procesos virtuales que tienen lugar directamente en el cerebro. Estos, hasta ahora, han sido accesibles a través de introspección. En la actualidad el incremento de los conocimientos de las funciones neuronales abren posibilidades reales para abordar este nivel de funciones con técnicas que registran directamente la actividad de las unidades neuronales generadoras de los fenómenos subjetivos. Esperamos que en un tiempo no muy distante la actividad neuronal, obtenida por vía analítica, podrá ser resintetizada de manera tal que la virtualidad de los fenómenos subjetivos sea objetivamente reproducida.

Los procesos subjetivos forman un conjunto impresionante de informaciones las cuales están permanentemente variando su grado de subjetivación. Existen instancias que van desde automatismos de un grado de muy débil subjetivación hasta otras que alcanzan un alto grado. Los altos niveles de subjetivación constituyen las percepciones sensoriales (exógenas) y las subjetivas (endógenas), mientras los bajos niveles de subjetivación corresponden a fenómenos subjetivos difusos pre o post perceptuales.

Las percepciones exógenas se generan a través de las conexiones sensoriales individuales -activación de los analizadores sensoriales correspondientes- y los elementos o fenómenos pertinentes de un determinado medio (interno o externo). Las percepciones endógenas -la habilidad de percibir o subjetivar fenómenos virtuales almacenados en los sistemas neuronales mnémicostienen lugar por medio de la activación de estos grupos neuronales, verdaderos depósitos informacionales, los cuales son puestos en condiciones de activar los sistemas neuronales capaces de reactivar la virtualización, o sea, resubjetivar la información almacenada.

Aunque las funciones neurales subyacentes a la virtualización no son totalmente conocidas, algo de esto es conocido. Por ejemplo, algunas condiciones necesarias para producir la resubjetivación de memorias almacenadas en unidades neuronales específicas.

Es un hecho conocido. Personas que han enfrentado una situación estimada como de peligro mortal, refieren una activación subjetiva especial. Estas personas han observado introspectivamente un panorama subjetivo secuencial, de ocurrencia espontánea, donde episodios vividos, muchos olvidados, aparecen en la pantalla subjetiva en una secuencia histórica, casi fílmica, y a gran velocidad. Probablemente este fenómeno es debido a una activación generalizada del Sistema Neuroendocrino.

Hay una cierta cantidad de asociaciones subjetivas espontaneas o involuntarias basadas en principios asociativos. Determinadas acciones o posturas pueden evocar situaciones donde análogas acciones estuvieron integradas total o parcialmente, aunque el contexto evocado haya sido totalmente diferente del contexto evocante. 
Determinadas percepciones exógenas o partes de ellas son capaces de evocar situaciones endógenas mnémicas en las cuales la situación exógena evocante o un elemento asociado de ella estuvo integrada espaciotemporalmente.

Algo similar sucede si procesos subjetivos exógenos evocan procesos subjetivos endógenos con los cuales se identifican o se intenta identificar el objeto o la situación percibida. Esto puede suceder cuando la percepción exógena es completamente nueva para el sujeto.

Las evocaciones anteriores son espontáneas e involuntarias. Pero existen evocaciones voluntarias. En estas condiciones los elementos evocados no aparecen inmediatamente al hacerse presente en el panorama subjetivo el elemento evocante (exógeno o endogeno). Aparece el recuerdo o la memoria de la "existencia" del elemento a evocar. Se está así frente a una "memoria de una memoria": elemento a evocar existe pero no se conoce su configuración perceptual. Dicho de otro modo, la evocación está dirigido por un elemento abstracto cuyas connotaciones sensoriales han sido olvidadas o son hipotéticas. En estas condiciones el cerebro, a través de sus funciones críticas, rastrea, compara las exigencias del modelo abstracto y las características ofrecidas por los diversos modelos concretos acumulados en las estructuras mnémicas. Estas comparaciones siguen diferentes estrategias y terminan también de diferentes modos, dependiendo de las condiciones de las funciones neurales.

\section{Homeoestasis Subjetiva}

El medio subjetivo requiere un cierto equilibrio necesario para mantener la unidad del ecosistema al cual pertenecen los individuos concretos, y la integridad funcional del Sistema Neuroendocrino. Este equilibrio no sólo es dependiente de la re- lación entre el medio interno y el medio externo, sino también es un equilibrio funcional del medio subjetivo. Esto es lo que hemos llamado "homeoestasis del medio subjetivo". Este equilibrio se refiere a la proporción entre los contenidos subjetivos representacionales de los medios externo e interno y de los contenidos subjetivos sin correlatos objetivos reales, ilusorios, alienados, fantásticos, hipotéticos, interpretativos, etc. La supresión total de cualquiera de estos dos polos produce una alteración de la actividad integrativa del Sistema Neuroendocrino, pues impide una de las funciones más importantes que este medio posee: la de operar anticipada y predictivamente sobre los medios objetivos. La ruptura del equilibrio homeoestático subjetivo al afectar al individuo opera sobre el ecosistema. En el caso del Homo sapiens, afecta al medio naturo-social con el cual los individuos interactúan, en primer lugar. Afecta la habilidad para adquirir conocimientos o aplicar estos conocimientos a finalidades prácticas, lo cual tiene una influencia inmediata en los medios objetivos. El desarrollo armónico del Sistema Neuroendocrino depende en una medida importante del medio subjetivo: la imaginación, la acumulación de información, el ejercicio de las habilidades abstractivas tienen directa influencia en el desarrollo neuronal, en las habilidades motoras, en las funciones viscerales y obviamente en el desarrollo emocional. Un caso interesante de alteración de la homeoestasis subjetiva es producida por una sobrecarga informacional, la cual tiene lugar cuando el cerebro trabaja un cierto tiempo bajo tres condiciones: necesidad de incorporar una gran cantidad de información, bajo un deficit temporal permanente y con un alto nivel motivacional. Esto genera una patología que ha sido denominada "neurosis informacional (Chananaschwili 1984, p.275 y sig.). Es justamente este medio subjetivo la sede de las habilidades reflexivas y del diálogo interno que cada individuo lleva a cabo. 
El medio subjetivo, como dijimos ya, es capaz de "resubjetivar" procesos subjetivos. El Sistema Neuroendocrino tiene, entonces, la propiedad de producir y reproducir los procesos virtuales. Esta propiedad permite la comunicación de los contenidos virtuales de la subjetividad, como también la organización anticipada de la interacción entre individuos, agrupados o no en conjuntos, con determinados aspectos de los medios objetivos. La operación sobre un futuro virtual, provee ventajas adaptativas enormes a cualquier especie que la posea.

La habilidad de la subjetividad de procesar sus propios productos, ha recibido la denominación de "conciencia", hecho este que ha contribuido eficientemente a asignarle la categoria de entidad. Con ello se ha enmascarado una importante función de la actividad integrativa del Sistema Neuroendocrino: la función de reproducir sus propios productos. La consciencia no es otra cosa que la resubjetivación de procesos subjetivos.

\section{Conclusiones}

La subjetividad es la tercera actividad integrativa del Sistema Neuroendocrino (Santibañez-H., 1984) de un tipo análogo a la reactividad y la plasticidad.

Los fenómenos subjetivos son fenómenos aprendidos, fenotípicos, de carácter virtual, generados en la interacción de individuos de diferentes especies, incluida Homo sapiens, con los diferentes medios con los cuales interactúan.

Como producto de la actividad neuronal los fenómenos subjetivos son perfectamente reales y objetivos. Sin embargo sus contenidos virtuales escapan a la linealidad temporo-espacial confiriéndoles una propiedad de supratemporalidad y supraespacialidad.
Estas propiedades permiten a los individuos operar fuera del presente -en el pasado o el futuro-, y de una manera general, fuera del tiempo.

La subjetivación es el proceso neurofisiológico -conocido hasta ahora sólo parcialmente- que permite a los individuos no sólo responder a los estímulos de los medios, sino que a convertirlos en fenómenos virtuales.

La información psicofisiológica muestra que la gran variedad de procesos subjetivos son elaborados estrictamente en diversas estructuras del cerebro, las cuales trabajan integradamente.

La subjetividad tiene variadas funciones. Entre ellas, la de producir estímulos que operan sobre el Sistema Neuroendocrino generando movimientos; la de reprocesar estímulos subjetivos (resubjetivación), lo cual determina una intensidad perceptual máxima, generalmente conocida como conciencia; la de abstraer elementos esenciales de los perceptos, generando ideas; la de reflejar la realidad generando conocimientos, o falseando la realidad produciendo ilusiones o alucinaciones.

La repetición de un proceso subjetivo ligado a un movimiento, termina por automatizar el movimiento de inhibición del proceso subjetivo. Los automatismos son el polo opuesto a la consciencia. Toda información que entra al Sistema Neuroendocrino entra en una gradiente que va desde la subjetividad al automatismo.

\section{Referencias}

Bloch, S., P. Orthous., y G. SANTiBÁÑEZ-H. 1987.: Effector patterns of basic emotions: a psichophysiological method for training actors. Journal Social Biological Structure. 10:1-19. 
BARLOW, H. B., 1995.: The neuron doctrine of perception. En M.S. Gazzaniga, ed. A Bradford book the M.I.T. Press Cambridge, Massachusetts, London England.

Cutting, J. E. 1987: Perception and information. Annual Review of Psychology, 38:61-90

Chananaschwili, M. M. y K. Hecht., 1984.: Neurosen Theorie und Experiment. Akademia Verlag - Berlín Pp. 258.

De WAAL, F. 2001.: The Ape and the Sushi master: cultural reflection by a primatologist. Basic book Pp. 433.

ECCLES, J. C. 1985: New light on Mind-Brain Problem: How mental events could influence neural events. In: Complex Systems. Operational Approaches, edited by H.Haken. Berlin, Heidelberg, New York, Tokyo (Springer Verlag).

ENGELS, F. 1975: Anti-Dühring. In: $M E W B d$. 20. Berlin (Dietz Verlag).

Engels, F. 1969: Ludwig Feuerbach. In: MEW. Bd 21. Berlin (Dietz Verlag).

Engels, F. Y K. MARX 1974.: Die heilige Familie. In: $M E W . B d$. 2. Berlin (Dietz Verlag).

EISLER, R. 1919:: Wörterbuch der philosophischen Begriffe. Berlin (E. S. Mittler u. Sohn).

Esch, H. E., SH. Zhang, M. V. SRINIVASAN, Y J. TANTS 2001.: Honeybee dances communicate distances measured by optic flow. Nature 411:581-582.

Farber, J. B. y P. Churland 1995.: Conciousness and Neurosciences: Philosophical and theoretical issues. In M. S. Gazzaniga The cognitive neurosciences. A Bradford book, the MIT Press, London England, p.12951305.
FINKE, R. N. 1985.: Theories relating mental imagery to perception. Psychological Bulletin 98:36-259.

FISCHER, R. 1975.:Transformation of consciousness. I. The perceptionhallucination continuum. Confinia Pychiatrica 8: 221 - 244.

Freud, S. 1970: Abriss der Psychoanalyse. Frankfurt $u$. Hamburg (Fischer Bücherei).

FrITH, C. D. 1979.: Consciousness, information processing and schizophrenia. British Journal of . Psychiatry 134: 225 - 235.

Gardner, B. T., R. A. Gardner 1969: Teaching sign language to a chimpanzee. Science 165: 664-672

GinsburG, H., B. Koslowski. 1976: Cognitive development. Annual Review of Psychology. 27: 29 - 61.

GreenberG, G. 1983.: Psychology without brain. The Psychological Record 33: 49-58.

GrIFFIN, D. R. 1976.: A possible window on the mind of animals. American Scientist 64: 530-53

GRIFFIN, D. R. 1978.: Prospect for a cognitive ethology. The Behavioral and Brain Sciences 4: 527-538 .

GrIFFIN, D. R. 1985.: Animal consciousness. Neurosciences and Biobehavioral Reviews 9: 615-622.

HAYES, K. y C. HAYES. 1971: Higher mental function of a home rised chimpanzee. In: Behavior of non human primates, edited by A. M. Schreier and F. Stollnitz. New York u. London (Academic Press)

Hilgard, E. L. 1980.: The trilogy of mind: cognition, affection and conation. Journal of History of Biological Sciences. 16: 107 117. 
HinTZMAN, D. L. 1986.: Shema abstraction in a multiple-trace memory model. Psychological Review 93: 411-428.

Hubel, D. H. y N. Wiesel 1961.: Integrative action in the cat's lateral geniculate body. Journal of Physiology (London). 115: 385 598.

HubeL, D. H. Y. N. Wiesel 1965.: Receptive field and functional architecture in two mono- striate visual areas (18 and 19) of the cat. Journal of Neurophysiology 28: 229289.

JACOBY, L. L. 1991.: A process dissociation framework: separating automatic from intentional uses of memory Journal of Memory and languaje 30:513-546.

JaCoBY, L. L, A.P. Yonelinas Y J. M. JENNINGS 1997.: Atention and automaticity. In scientific approachs to consciousness Edited by J.D. Cohen and J.W. Schooler. Lawrence Erlbaum Associates. Publishec Mahwah, New Jersey Pp. 538.

James, W. 1907: The Principles of Psychology Vol. 2. New York (Henry Holt).

JANET, P. 1921.: L'automatisme psychologique Essai de Psychologie expérimentale. Libraine Felix Alcan, Paris. Pp. 496.

John, E. Y R., E. L. Schwartz 1978.: The neurophysiology of information processing and cognition. Annual Review of Psychology. 29: 1 - 29.

Kinght, R. y M. GRabowecky, 1995. Escape from linear time: prefrontal cortex and conscious experience. In the cognitive neurosciences. Editado por M.S. Gazzaniga. A Brandford Book, The MIT Press. Cambridge Massachusetts, London England.
KONORSKI, J. 1967: Integrative activity of the brain. Chicago y London (The University of Chicago Press).

Koref-Santibáñez, S. y. G. Santibáñez-H. 1986.: Adaptation and individual adaptation. Introduction to the physiopathology of neurotic states, edited by G. Santibanez-H. and M. Lindemann. Leipzig (Georg Thieme Verlag).

Levi-Strauss, C. 1973.: Das wilde Denken. Frankfurt am Main (Suhrkamp Verlag).

MARX, K. 1956.: Aus der Kritik der Hegelschen Rechtsphilosophie. In MEW. $B d$. 1. Berlin (Dietz Verlag).

MARx, K. 1974.: Grundrisse der Kritik der politischen Ökonomie. Berlin (Dietz Verlag)

MARX, K. y F. EnGels 1969.: Die deutsche Ideologie. In: $M E W . B d .3$. Berlin (Dietz Verlag)

MARX, K. y F. Engels: Werke. 1973.: Ergänzungsband. $B d .1$ u. 2. Berlin. (Dietz Verlag).

McKAY, D. M. 1967.: Ways of looking at perception. Models of perception of speed in visual form, edited by F. O. Smith. Boston (MIT Press) (Reprinted in Perceptual processing, edited by I. C. Dowell. Appleton Century Croft 1970)

McKaY, D. M. 1978: The dynamic perception. Cerebral correlation of conscious experience, edited by P. A. Buser and A. Rangeul-Buser. INSERM Symposium N' 6. Amsterdam: Biomedical Press. Elsevier-North Holland.

Medoev, A. G. 1979: Gravinrej naskalach. Alma-Ata (Dzhalin).

Moore, R. J. y N. J. LenN (1971).: A retinohypothalamic projection in the rat: Journal of Comparative Neurology 146: 1 14 
Morgenau, H. 1984.: The Miracle of Existence. Woodbridge (Conn). (Ox Bow Press).

Mountcastle, V. 1986.: The neural mechanisms of cognitive functions can now be studied directly. Trends in Neurosciences. October p. 505-508.

PARKS, E. T. 1986.: Illusory figures, illusory objects, and real objects.: Psychological Review. 93: 207-213.

Pawlow, I. P. 1953.: Sämtliche Werke. Bd. 3. Berlin (Akademie Verlag).

Phillipson, O. T. Y J. P. Harris 1985.: Perceptual changes in schizophrenia: a questionnaire survey. Psychological Medicine. 15: 859 - 866

Poulain, B., G. Baux y L. Tauc 1986.: The quantal release at a neuro-neural synapsis is regulated by the contents of acetylcholine in the presanaptic cell. Journal de Phypiologie. Paris 81: 270-277

PREMACK, D. 1976.: Intelligence in ape and man. Hillsdale, N. J. (Lawrence Erlbaum Associates).

RaWlings, J. N. P. 1955.: Association across time: The hippocampus as a temporary memory store. The Behavioral and Brain Sciences. 8: 479-496.

Real Academia Española 1956.: Diccionario de la Lengua Española. Real Academia Española, XVIII Edición. Madrid.

RosH, E. H. 1973.: On internal structure of perceptual and semantic categories. Cognitive development and the acquisition of language, edited by T. E. Moore. New York (Academic Press).

Rosin, R. 1978.: The honey-bee 'language' controversy. Journal of Theoretical Biology. 72 586-602.
Rotenberg, A./R. S. Sobel 1980.: Adaptation and cognition. An experimental study of creative thinking. Journal of nervous and mental desease. 168 p. $370-374$.

Rumbaugh, D. M. y, T. V.Gill, E. von Glaserfeld, H. WARNER Y P. PISANI (1975).: Conversation with a chimpanzee in a computercontrolled environment. Biological Psychology. 10: 627 -640.

SANTiBÁÑEZ-H., G. 1976.: Subjective gnostic specific and unspecific activating aspects of emotion and motivation: emoving reflexes. Brain and Behavior. Research Monographic Series, edited by W. Haschke, Jena (Gustav Fischer Verlag). 6: 191-209

SANTIBÁÑEZ-H., G. 1984.: Principal functions of the neuroendocrine system: the functional basis of the integrative activity of the brain. Introduction to the physiopathology of neurotic states, edited by G. Santibáñez-H. and M. Lindemann. Leipzig (Georg Thieme Verlag).

Santibañez-H., G. 2000.: Acerca de la Ontopsicología. Revista de Psicología, Universidad de Chile, 9:171-184.

Santibañez-H., G. 2001.: Bases Psicofisiológicas de la gnoseogenesis. Revista de Psicología, Universidad de Chile, 10:151-176.

Santibáñez-H., G. y S. Bloch 1986.: A quantitative analysis of emotional effector patterns and their feedback. The Pavlovian Journal of Biological Sciences. 21: 108116.

SAntibañez-H., G. Y H. Osorio H. 1998.: El Objeto de la Psicología I.: la historicidad del objeto de la psicología. Revista de Psicología, Universidad de Chile, 7:89-104. 
SANTIBAÑeZ-H., G. y H. Osorio H. 1999.: El Objeto de la Psicología II. Revista de Psicología, Universidad de Chile, 8:7-29.

Savage-Rumbaugh, E. S., . M. Rumbaugh y S. BOYSEN 1978.: Symbolic communication between two chimpanzees. Science. 201: $640-644$.

Savage-Rumbaugh, E. S., .D M. Rumbaugh y S.BOYSEN 1980.: Do apes use language? American Scientist. 68: 49 - 61.

SEARLy, J. R. 1990.: The problem with consciousness.bbs@soton.ac.uk

SEARLY, J. R. 1992.: The rediscovery of the mind. Cambridge, Mass: MIT Press p. 97-99.

Setchenow, I. (1863) 1965.: Selected physiological and psychological works. Moskau (Foreign Languages Publishing House).

SHAFFER, L. H. 1976.: Intention and performance. Psychological Review 83: 375-393.
SMith, C. V. M. 1978.: Charles Darwin, the origin of consciousness and Panpsychism. Journal of History of Biology. 11: 245-267.

Smith, N. M. 1984.: Fundamentals of Interbehavioral psychology. The Psychological Record. 34: 479-494.

Walker, S. T. 1983.: Animal thought (International library of psychology) Routledge and Kegan Paul. London, Boston Melbourne and Henley Pp. 437.

Wilson, D. L. 1972.: On the nature of consciousness and of physical reality. Perspectives in Biology and Medicine. 2: $569-581$.

Wise, L. Z. Y, D. P. I. IRVINE 1985.: Topographic organization of interaural intensity difference sensitivity in deep layers of cat superior colliculus: implication for auditory spatial representation. Journal of Neurophysiology. 54: 185-211. 